RESENHA: RAVECCA, Paulo. The politics of political science: re-writing Latin American experiences. New York: Routledge, 2019. 292 p.

\title{
Uma história comparada da ciência política na América Latina
}

A comparative history of political science in Latin America

\section{Emerson do Nascimento' ${ }^{1}$}

Não é fácil determinar o momento preciso de nascimento da ciência política na América Latina. A dificuldade em diferenciar os estudos realizados por pesquisadores de outras ciências como a história, a filosofia e a sociologia da ciência política reconhecida como disciplina autônoma compreende parte dessa limitação. O desenvolvimento político e social desigual da região, somado às peculiaridades contextuais e às particularidades históricas dos países latino-americanos, também tem muito a nos dizer sobre o sentido e as formas de se fazer ciência política aqui - em sentido lato e distinto daquela que é produzida nas academias norte-americana e europeia.

Se, por um lado, a datação desse "nascimento" é difícil, o mesmo não se pode dizer sobre o nascente interesse da ciência política, sobretudo aquela produzida na América Latina, pelo desenvolvimento de uma espécie de exercício de autorreflexão. Este fenômeno

Professor Associado do Instituto de Ciências Sociais e do Programa de Pós-graduação em Sociologia da Universidade Federal de Alagoas (UFAL), Maceió, AL, Brasil. E-mail: 
pode ser verificado por meio do número crescente de grupos de pesquisa orientados pelo estudo da epistemologia e da metodologia da ciência política na região, bem como pelo avanço significativo no número de publicações específicas sobre o tema e a produção de dossiês especializados nos últimos dez anos.

O livro The politics of political science: re-writing Latin American experiences, de Paulo Ravecca, inicialmente apresentado como tese de doutorado em ciência política à York University, pode, perfeitamente, ser inserido como uma contribuição prestigiosa à explosão crescente de interesse pela autorreflexão dentro de nosso campo. Questionando a baixa reflexividade da ciência política contemporânea acerca de seus approaches teóricos e metodológicos, o trabalho de Ravecca propõe perfazer uma história da ciência política tomando como referência menos os fatores internos à disciplina e mais os fatores externos e, portanto, contextuais de desenvolvimento da ciência política em cada país ou região. É nesse sentido que o autor se dedica à investigação empírica da trajetória disciplinar da ciência política em dois países latino-americanos: Chile e Uruguai.

O que interessa ao autor não é apenas comparar as trajetórias disciplinares nacionais, mas explorar a relação entre a institucionalização da ciência política nesses países e o contexto local, mais precisamente, sua relação com os regimes de exceção instalados nos países ainda na década de 1970. Seu principal esforço compreende refutar a tese convencional de que, na América Latina, o desenvolvimento da ciência política haveria sido interrompido pelo advento das ditaduras militares. Na contramão dessa interpretação, Ravecca argumenta que não há uma linearidade entre ciência política e democracia. Em outras palavras: falar em ciência política não implica, necessariamente, falar em ciência política democrática. É a partir dessa perspectiva que o autor pensa o desenvolvimento da disciplina na região, considerando um modelo hermenêutico relacional e complexo que sobrepõe o discurso científico e o contexto político, mostrando o quanto há de poder (prático e discursivo) no conhecimento científico produzido pelos cientistas políticos chilenos e uruguaios do período. 
Ao contrário do que faz sugerir o mainstream da ciência política contemporânea - de cunho liberal e neopositivista -, o livro explora as intrincadas relações entre poder e conhecimento no seio da disciplina. Trata-se, a bem da verdade, de uma espécie de incursão no que se convencionou chamar de uma "política da ciência política", expressão que Ravecca toma do trabalho de W. H. Morris-Jones (1983) e que cabe com precisão aos seus propósitos aqui, a saber: construir uma perspectiva alternativa de narração da história da ciência política na América Latina, com destaque para a comparação dos casos chileno e uruguaio, onde o pesquisador exerce hoje suas atividades de docência e pesquisa.

Amparado pelo conceito de racionalidade complexa, que ele próprio cria a partir da adoção devidamente apropriada do arsenal analítico da teoria crítica, Ravecca explora as vicissitudes do processo de institucionalização da disciplina na região, não a partir de uma perspectiva endógena ou exógena, mas exclusivamente dinâmica. E esta é, sem dúvidas, uma perspectiva diferenciada daquela com que estamos acostumados a pensar a história da ciência política - de dentro para fora, com destaque para a narrativa de tipo paroquialista, apoiada sobre as peculiaridades de cada nação ou, ainda, de fora para dentro, a partir da prescrição de uma epistemologia única e de um mapa de rota comum ao que se produz sob o rótulo de ciência política por todos os demais países.

A ênfase desmedida sobre as peculiaridades nacionais restringe o alcance das deduções que se pode fazer do processo de desenvolvimento da ciência política na América Latina. Por outro lado, o foco sobre uma espécie de história única da disciplina não é menos problemático, visto que sugere uma apreensão equivocada do campo e, na maioria das vezes, insiste em tomar a parte pelo todo: a trajetória de desenvolvimento da ciência política norte-americana, seu background teórico e metodológico, são tomados como parâmetros de aferição de rigor analítico e cientificidade.

Ravecca problematiza que uma história da ciência política latino-americana que recomponha essa narrativa a partir de outro ângulo (o da relação entre poder e saber) deve, por base, questionar 
a natureza e os limites dos componentes conceituais e metodológicos que constituem o discurso disciplinar dominante na região. Esse exercício se faz necessário, segundo o autor, não somente para conhecermos melhor o impacto que os fatores contextuais endógenos e exógenos têm sobre as teorias e os métodos que desenvolvemos, mas também para melhor refletirmos sobre as práticas e os valores que orientam nossa profissão. Em outras palavras: para quem e pelo que temos investido nossos esforços de pesquisa e de formação profissional?

A relação entre ciência política e democracia é o ponto de inflexão dessa interrogação e ponto de partida para a mirada reflexiva e de diferenciação que a obra inaugura. O que se questiona aqui não é, portanto, a ausência de autorreflexividade por parte da ciência política produzida nos Estados Unidos, o que seria uma absoluta inverdade. O que se questiona, de fato, é o alcance dessa narrativa e a limitação de sua extensão à história da ciência política nos países latino-americanos.

De acordo com Ravecca, persevera na área, de modo velado, o entendimento de que todo conhecimento produzido sobre o mundo político nos países de colonização ibero-hispânica, antes do momento de profissionalização e expansão da ciência política anglo-saxã sobre o continente, seria de tipo não científico. Essa perspectiva tem sido defendida em favor de uma história única da disciplina, apoiada em fatores estruturais exógenos, entre eles a expansão da terceira onda de democratização, a globalização e a hegemonia estadunidense. Essa hipótese é problemática visto que, além de apelar para uma espécie de amnésia disciplinar, privilegia uma narrativa de caráter universalista e unitária para o desenvolvimento da ciência política, posicionando a experiência norte-americana numa perspectiva privilegiada. Essa proposta epistemológica suprime as experiências distintas de profissionalização e institucionalização do campo nos países latino-americanos em favor da narrativa hegemônica estadunidense.

Contudo, por que essa virada autorreflexiva chegou tão tardiamente à ciência política (se comparada às tradições reflexivas da 
sociologia e da antropologia, por exemplo)? O argumento do livro recai sobre a influência do pensamento positivista e liberal da ciência política norte-americana que, a partir da segunda metade do século $\mathrm{XX}$, passou a se consolidar nos cursos de graduação e pós-graduação de ciência política na América Latina. Essas transformações epistemológicas estariam relacionadas, segundo Ravecca, às transformações de poder que atravessaram a região nesse período em diferentes níveis: o crescimento da influência econômica e cultural dos Estados Unidos depois da Guerra Fria; o colapso do socialismo da União Soviética; a emergência da hegemonia neoliberal; o trauma advindo das rupturas institucionais e das ditaduras implantadas na região ao longo da década de 1970; os moldes como se deram as transições para a democracia; e a própria transmutação das instituições políticas locais ao longo desse período.

À despeito de suas pretensões de neutralidade, distanciamento e objetividade, a ciência política ainda é uma atividade humana e, nos dizeres do autor, por esse motivo, ela afeta e se deixa afetar pelas dinâmicas políticas e sociais. Para carregar seu argumento de embasamento empírico, o autor toma para análise dois casos em perspectiva comparada: o processo de constituição e institucionalização da ciência política no Chile e no Uruguai. Por meio desse exercício comparativo e fazendo uso ainda de métodos inferenciais diversos, a obra explora as interconexões entre esses variados fatores e o tipo de conhecimento produzido pela ciência política chilena e uruguaia.

$\mathrm{O}$ autor demonstra de que forma esses elementos contextuais interferiram e configuraram o tipo de ciência política produzida em cada um desses países. No caso do Chile, a ciência política se consolidou durante a ditadura militar, ao contrário do Uruguai, que só conheceu seu primeiro curso de mestrado na área dez anos após sua redemocratização. Para Ravecca, o caso chileno figuraria uma situação excepcional, caracterizada pela produção de uma espécie de "ciência política autoritária" - uma geração de intelectuais neoconservadores que combinou autoritarismo e liberalismo de forma institucionalizada e até sofisticada. O caso chileno contraria 
o que aconteceu à maior parte do conhecimento produzido pelas ciências sociais latino-americanas durante o período. No caso específico da trajetória da disciplina no Uruguai, a ditadura agiu de modo distinto, apelando à censura e à negação das ciências sociais, o que interferiu diretamente no desenvolvimento da ciência política uruguaia, atrasando seu processo de consolidação que só se dará muito mais tardiamente.

O exame dessas experiências extrapola em muito o que compreende os interesses particulares da academia chilena e uruguaia e oferece ferramentas analíticas para pensar outros cenários possíveis de problematização e interpretação das relações de poder dentro da ciência política na América Latina. Para analisar o conteúdo dessa produção, Ravecca recorre à análise bibliométrica, mas também apela para outros recursos metodológicos menos convencionais dentro da ciência política, como a análise do discurso e, até mesmo, a produção de uma espécie de autoetnografia de sua formação enquanto cientista político, construída a partir de seu olhar desnaturalizado de pesquisador queer (é assim que o próprio Ravecca se apresenta ao longo do texto) e de sua percepção desterritorializada de estudante de doutorado em trânsito.

Há, sem dúvidas, muita ousadia metodológica no exercício analítico empreendido pelo pesquisador, seja pelo argumento desafiador que ergue contra o mainstream da ciência política contemporânea e seu discurso triunfalista, seja pela forma como se apropria de suas ferramentas analíticas ao longo do texto, incorporando à análise um conjunto de elementos que não poucas vezes são ignorados pela ciência política de caráter hegemônico: os planos da subjetividade, dos afetos, dos discursos e das próprias experiências pessoais do pesquisador. Um estudo provocativo que não preza em nenhum momento por qualquer tipo de monismo teórico ou metodológico.

Ravecca questiona a ciência política não pelo dito, mas pelo que reside implícito no centro dos discursos de poder na região. Nesse sentido, além de uma forte influência da tradição crítica no argumento central do seu trabalho, há uma forte inspiração de natureza foucaultiana na forma como ele constrói uma espécie de 
arqueologia do nosso campo de conhecimento. Do mesmo modo, é inegável ainda o compromisso intelectual do autor com outras tradições pouco exploradas na ciência política contemporânea, como os ditos estudos pós-coloniais, que aqui encontram eco na propositura de um projeto de reescritura descentrada da história da ciência política latino-americana apoiada, simultaneamente, na caracterização dos contextos locais somados aos fatores transversais dos Estados-nações da região.

Há exatos 16 anos, Giovanni Sartori (2004), um dos pais da ciência política, perguntava-se: para onde vai a ciência política? Naquele momento, um dos cientistas políticos mais importantes do século, que ajudou com sua obra a configurar a área, denunciava que a disciplina estaria sofrendo um processo progressivo de americanização, o qual podia ser evidenciado pela ênfase desmedida sobre o método e a quantificação em detrimento do desenvolvimento de problemas de pesquisa de fato relevantes. O diagnóstico de Sartori ecoou profundamente no campo e deu o pontapé em favor da constituição de um espaço de autorreflexão teórica e metodológica dentro da disciplina. De lá pra cá, o cenário mudou bastante, haja vista que foram criados muitos grupos de pesquisa especializados sobre metodologia aplicada à ciência política, sobre a história da disciplina e sobre seus cursos de desenvolvimento e profissionalização.

Seguindo os passos de Sartori, Ravecca questiona o descompasso entre os ganhos metodológicos registrados na ciência política nas duas últimas décadas e nosso hábito ainda restrito de discutir as bases epistemológicas que sustentam a produção de conhecimento na área. Se, por um lado, essas mudanças trouxeram ganhos relevantes de qualidade científica para a ciência política como um todo, por outro, limitaram o desenvolvimento de uma história compreensiva da ciência política e obliteraram, por mais contraditório que isso possa parecer, o conjunto intrigante das relações de poder dentro da própria disciplina e, nesse sentido, o livro em questão é uma contribuição significativa, visto que provoca a ciência política, retirando-a de sua tradicional condição de conforto. 


\section{Referências}

MORRIS-JONES, Wyndraeth Humphreys. The politics of political science: the case of comparative legislative studies. Political Studies, n. 31, p. 1-24, 1983.

RAVECCA, Paulo. The politics of political science: re-writing Latin American experiences. New York: Routledge, 2019. SARTORI, Giovanni. ¿Hacia dónde va la ciencia política? Revista Política y Gobierno, v. 11, n. 2, p. 349-354, 2004.

Recebido em 24 de março de 2018 Aprovado em 08 de agosto de 2020 